\title{
Variation of bilateral superficial palmar arch - A case report with its clinical significance
}

\author{
Sonal Govindwar ${ }^{1}$, Swapna Chavan ${ }^{2 *}$ \\ ${ }^{1}$ Assistant Professor, Nanded Rural Dental College \& Research Center, Nanded, Maharashtra, INDIA. \\ ${ }^{2}$ Assistant Professor, Department of Anatomy, HBT Medical College and Coopar Hospital, Vile Parle, West Mumbai, Maharashtra, INDIA. \\ Email: sonal.govindwar@gmail.com, swapna.chavan2012@gmail.com
}

Abstract The anastomoses between radial and ulnar arteries in the palm play a significant role in diseases of the palm through collateral circulation. During routine dissection of the upper limb of a 45 -year-old male cadaver, we observed the bilateral incomplete superficial palmar arch (SPA), where both the superficial branches of radial and ulnar artery were present but completely fails to join with each other to form a complete SPA. In right hand, the superficial palmar branch of the radial artery entered the hand above the thenar muscles and provided palmar digital branches to the radial side of the index finger and the ulnar side of the thumb, without any contribution to the SPA. The superficial branch of the ulnar artery gave origin to three common palmar digital arteries to supply the contiguous sides of the index, middle, ring and little fingers. In left hand, both the arteries did not give any branches and ends in the straight course without anastomosis.

Key Words: Radial artery, Superficial palmar arch, Ulnar artery.

*Address for Correspondence:

Dr. Swapna Chavan, Assistant Professor, Department of Anatomy, HBT Medical College and Coopar Hospital, Vile Parle, West Mumbai, Maharashtra, INDIA.

Email: swapna.chavan2012@gmail.com

Received Date: 19/04/2017 Revised Date: 21/06/2017 Accepted Date: 10/07/2017

DOI: https://doi.org/10.26611/1001421

\begin{tabular}{|c|c|}
\hline \multicolumn{2}{|c|}{ Access this article online } \\
\hline Quick Response Code: & \multirow{2}{*}{$\begin{array}{l}\text { Website: } \\
\text { www.medpulse.in }\end{array}$} \\
\hline & \\
\hline & $\begin{array}{c}\text { Accessed Date: } \\
04 \text { November } 2017\end{array}$ \\
\hline
\end{tabular}

INTRODUCTION

The anastomoses between radial and ulnar arteries in the palm play a significant role in diseases of the palm through collateral circulation. During routine dissection of the MBBS students we have seen that, the both hand of a 45 year-old male cadaver, showed variation in the formation of the superficial palmar arch (SPA). [The superficial arteries of the hand formed several diversified patterns that permitted into well-defined categories. About two-third of the SPA is formed by the ulnar artery alone; a further third is completed by the superficial palmar branch of the radial artery and a third either by the arteria radialis indicis or by the princeps pollicis or by the median artery. A classic type of SPA in which the superficial branch of the radial artery joins the superficial branch of the ulnar artery is found only in $34.5 \%$ of the cases. There are many reports regarding formation of SPA. In a study by Coleman et al. ${ }^{1}$, the complete arch was found in $78.5 \%$ of the cases and incomplete arch in the remaining $21.5 \%$, and this formed a major underlying factor in the aetiology of digital ischaemia. Ikeda et $a l^{2}$. conducted stereoscopic arteriography of 220 cadaver hands and reported complete SPA in $96.4 \%$ of the cases, and only $3.6 \%$ had an incomplete arch. Gellman et al. showed a complete SPA in $84.4 \%$ and Al Turk and Metcalf reported complete SPA in $84 \%$ of the cases.

\section{CASE REPORT}

In the present case, we observed following types of variation in superficial palmar arch.

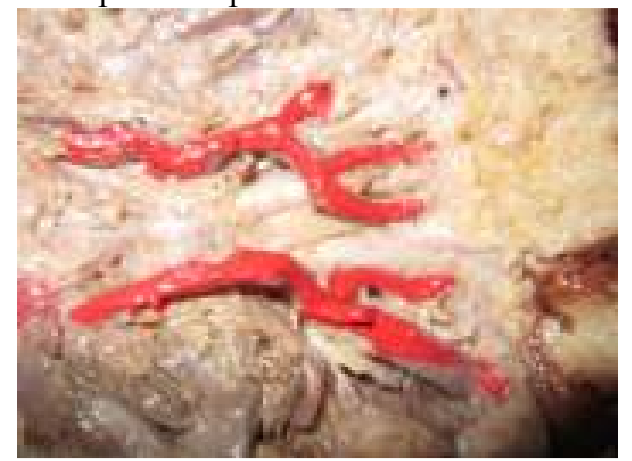

Figure 1: Showing the incomplete right superficial palmar arch 
Figure no. 1 showing the variations in the formation of superficial palmar arch on right side, where both the branches i.e. superficial palmar branch of the radial and ulnar artery were present but, fail to anastomose with each other. The superficial palmar branch of the radial artery entered the hand through the thenar muscles at the flexor polices brevis and passed superficial to the thenar muscles and provided palmar digital branches to the radial side of the index finger and the ulnar side of the thumbSuperficial branch of ulnar artery was giving three branches and superficial branch of radial artery was giving off two branches.

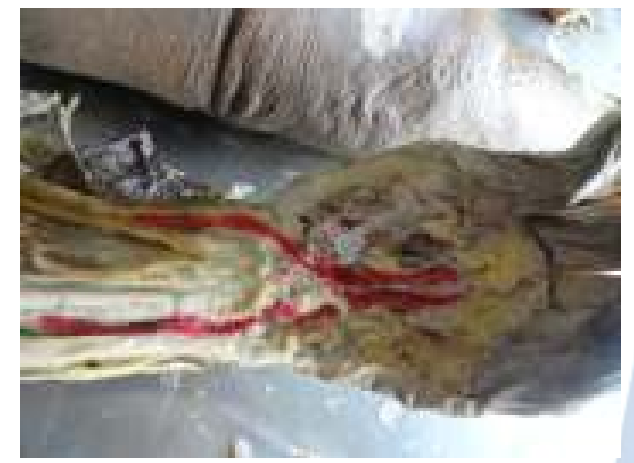

Figure 2: Showing the incomplete of left superficial palmar arch

Figure No. 2 showing the incomplete superficial palmar arch on left side. Here, the superficial branches of radial and ulnar were present without any branching, but they did not unite with each other, thus there was absence of superficial palmar arch. Deep palmar arch in both the hands was normal.

\section{DISCUSSION}

Figure no. 1 and 2, was showing the cases where the both the superficial palmar branches of radial and ulnar artery were present, without anastomosing with each other. This type of variation was classified as a type A of group II, as per the Coleman and Anson (1961) ${ }^{1}$ classification. This type of variation was observed by patnaik, V.V.VG, et al $(2002)^{3}$, in $3.2 \%$ cases, suleyman murat tagil et al $(2007)^{4}$, in $3.2 \%$ cases, sanjay kumar Sharma et al $(2013)^{5}$, in $10 \%$ cases, where as Challa. Ratna Prabha et al $(2014)^{6}$ presented a case report where this type of arch was observed. In present study such type of arch was observed in $13.4 \%$ cases. The explanations for the arterial variations are based on classical outline of arterial development. Arey7 is of the view that the anomalies of blood vessels may be due to the choice of the unusual paths in the primitive vascular plexuses, the persistence of vessels normally obliterated, incomplete development or absorption of the parts usually distinct.

\section{CONCLUSION}

The existence of both common and rare anatomic variations in the formation of superficial palmar arch as well as the absence of collateral circulation between ulnar and radial arteries necessitates the proper knowledge of vasculature of the hand in order to avoid or minimize the risk of complications during vascular surgeries or reconstructive surgeries in the hand.

\section{REFRENCES}

1. Coleman, S. and Anson, J. (1961): Arterial pattern in hand based upon a study of 650 specimens. Surgery Gynaecology Obstetrics. 96: 43-54.

2. Ikeda A, Matsumoto S, Yoshii I, Ikeda K. Comparative anatomical studies of arteriographs of the hand and foot in primates including man. Kaibogaku Zasshi 1993; 68:263-280.

3. Patnaik VVG, Kalsey G, Singla RK (2002). Palmar arterial arches-a morphological study. Journal of Anatomical Society of India, 51: 187-193.

4. Suleyman murat tagil et al. Variations and clinical importance of the superficial palmar arch. S.D.U. Tip Fak. Derg. 2001:14(2)//11-16.

5. Sanjay Kumar Sharma, Arun Prasad Singh, Sanjeev Kumar Sinha, Jai Jyoti. Palmar arterial arches- a morphological study. Journal of Evolution of Medical and Dental Sciences 2013; Volume 2, Issue 36: Page 6895- 6902.

6. Challa. Ratna Prabha, Bvindala Bhagalakshmi, Namburi Bhanu Sudha Parimala, Chandaka Swathi Poornima. Incomplete Superficial Palmar Arch - Clinical Significance IOSR Journal of Business and Management, 2014; Volume 16, Issue 4. Ver. III: PP 07-09.

7. Arey, L.B. Developmental anatomy In: Development of the arteries. 6th Edn W.B. Saunder's Co. Philadelphia. : 375-7 (1957).

\section{Source of Support: None Declared} Conflict of Interest: None Declared 